\title{
Selenium Treatment Effect in Auto-Immune Hashimoto Thyroiditis in Macedonian Population
}

\author{
Nevena Manevska ${ }^{a}$,, Sinisa Stojanoski ${ }^{a}$, Tanja Makazlieva ${ }^{a}$
}

\begin{abstract}
Background: Selenium (Se), a necessary trace mineral for humans, has the highest concentration in the thyroid gland and is known of its anti-oxidant and anti-inflammatory properties. Many studies have reported that Se has a close relationship with auto-immune Hashimoto's thyroiditis (HT), characterized by the presence of anti-thyroid peroxidase (aTPO) auto-antibodies.
\end{abstract}

Methods: Five hundred thyroid patients, males and females, mean age $46 \pm 19$ years, with diagnosed HT, were included in the study. Euthyroid forms of HT were treated with Se only, while patients with thyroid-stimulating hormone $(\mathrm{TSH})>10 \mu \mathrm{IU} / \mathrm{mL}$ were treated with both substitutional therapy of levothyroxine and Se.

Results: In around $37 \%$ of the patients treated with Se $3 \times 50 \mu \mathrm{g} /$ day with aTPO $>1,000 \mathrm{IU} / \mathrm{mL}$, aTPO remained unchanged after 12 months, while $24.16 \%$ had aTPO $<500 \mathrm{IU} / \mathrm{mL}$ and $38.20 \%$ had aTPO between 500 and 1,000 IU/mL. Eighty-three out of 150 $(55.33 \%)$ patients treated with Se $2 \times 50 \mu \mathrm{g} /$ day with aTPO between 500 and $1,000 \mathrm{IU} / \mathrm{mL}$ responded. More than half of the patients $(91 / 172,52.90 \%)$ with aTPO $<500 \mathrm{IU} / \mathrm{mL}$ treated with Se $50 \mu \mathrm{g} /$ day normalized in 1 year. In hypothyroid group of patients, 12 months after treatment with levothyroxine and Se, $47.18 \%$ were responders with aTPO $>1,000 \mathrm{IU} / \mathrm{mL}$, while $79.20 \%$ with aTPO between 500 and $1,000 \mathrm{IU} / \mathrm{mL}$. In euthyroid group (Se only), the biggest response $(30.56 \%)$ was seen in patients with the highest titer of aTPO $>1,000$ $\mathrm{IU} / \mathrm{mL}$.

Conclusion: Se treatment is effective in reducing the levels of aTPO in patients with HT, alone or in combination with levothyroxine. This is due to the anti-inflammatory and anti-oxidant effect of Se. Our study promotes the concept of Se treatment in patients with euthyroid or hypothyroid state, with increased titers of aTPO.

Keywords: Selenium; Hashimoto thyroiditis; Thyroid; aTPO

Manuscript submitted March 11, 2019, accepted March 20, 2019

anstitute of Pathophysiology and Nuclear Medicine, University of Ss. Cyril and Methodius, Skopje, Macedonia

${ }^{b}$ Corresponding Author: Nevena Manevska, Institute of Pathophysiology and Nuclear Medicine, University of Ss. Cyril and Methodius, Str. Mother Theresa, No. 17, 1000 Skopje, Macedonia. Email: dr.nmanevska@gmail.com

doi: https://doi.org/10.14740/jem551

\section{Introduction}

Selenium (Se) is an essential trace element that is required for the correct functioning of the immune system, naturally present in many foods, including Brazil nuts, organ meat, muscle meat, cereals, shellfish and fish and available as a dietary supplement, with a recommended daily intake for adults of $55 \mu \mathrm{g}$ [1]. It exists in two forms: inorganic (selenate and selenite) and organic (selenomethionine and selenocysteine). In human tissues, the most common form is selenomethionine, where it can be incorporated nonspecifically with the amino acid methionine in body proteins. Skeletal muscle is the major site of Se storage (approximately $28-46 \%$ of the total Se pool) [2].

$\mathrm{Se}$, a necessary trace mineral for humans, has the highest concentration in the thyroid gland and is known of its antioxidant and anti-inflammatory characteristics [3]. Hormones and growth factors regulate the expression of selenoproteins and conversely, Se supply modulates hormone actions. At least 30 proteins are Se-dependent, including glutathione peroxidase enzyme, iodothyronine deiodinases enzyme (converting thyroxine to bioactive 3 -iodothyronine) and thioredoxin reductases (TRs) [4], which implies that individuals with Se deficiency will further on be closely associated with thyroid damage and lymphocytic inflammation. Many studies have reported that Se has a close relationship with auto-immune Hashimoto's thyroiditis (HT), characterized by the presence of anti-thyroid peroxidase (aTPO) auto-antibodies. The therapeutic effect of Se supplementation in HT treatment remains unclear.

The objective of the present study was to determine the efficacy of Se supplementation for the treatment of HT.

\section{Materials and Methods}

A prospective longitudinal randomized interventional study was performed at the outpatient's thyroid unit of the Institute of Pathophysiology and Nuclear Medicine in Skopje. The study was conducted in compliance with the Ethical Standards of the responsible institution on human subjects as well as with the Helsinki Declaration. We enrolled 500 consecutive thyroid patients, both males and females, at ages of $19-78$ years, mean age $46 \pm 19$ years, with diagnosed HT, determined by ultrasonographic features of the thyroid gland and elevated level of aTPO $(10.0-35.0 \mathrm{IU} / \mathrm{mL})$. Standard laboratory tests were investigated, such as the level of free thyroxine $\left(\mathrm{FT}_{4}\right)$, 


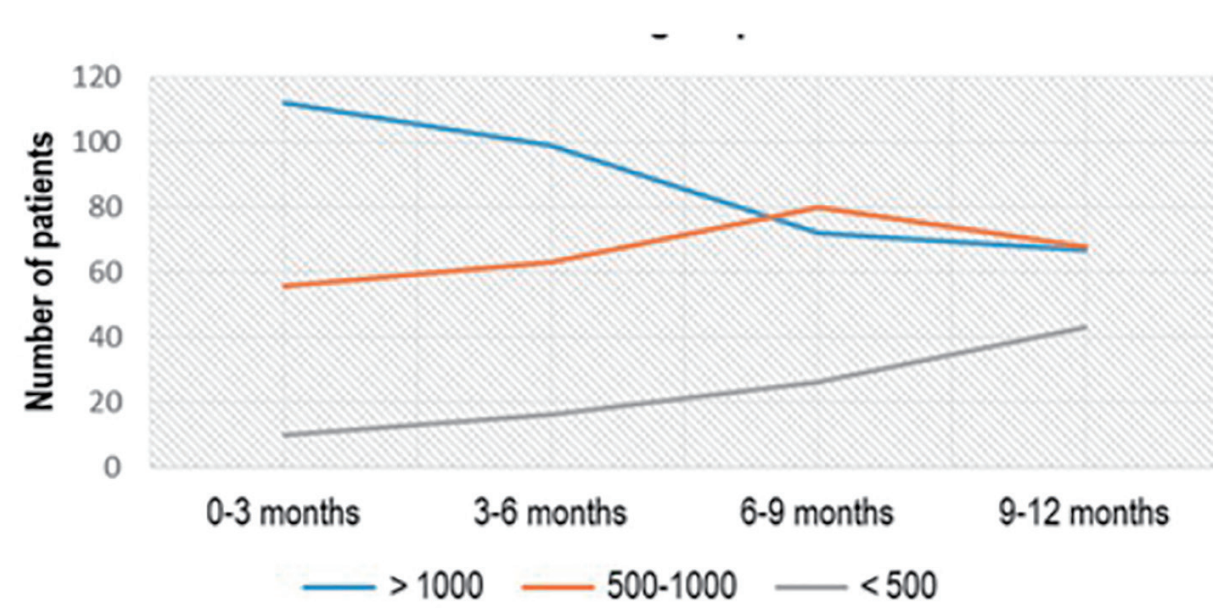

Figure 1. aTPO level after Se $(3 \times 50 \mu \mathrm{g})$ administration in the subgroup with initial aTPO > 1,000 IU/mL. aTPO: anti-thyroid peroxidase; Se: selenium.

thyroid-stimulating hormone (TSH) and aTPO (immunochemiluminescent method was used, with Immulite 2000). The ultrasonographic examination was performed by three observers individually, all with over 10 years of experience in the field of thyroid gland ultrasonography, and gland volume and change in the echogenicity in correlation with aTPO levels were analyzed. The ultrasonography was performed using linear sonda for small organs, with frequency of $7.5-10 \mathrm{MHz}$ (LN 12-3, Philips HD6).

The inclusion criteria were: patients with euthyroid function (TSH: 0.4 - $4.5 \mu \mathrm{IU} / \mathrm{mL} ; \mathrm{FT}_{4}$ : 11.0 - $25.0 \mathrm{pmol} / \mathrm{L} ; \mathrm{FT}_{3}$ : $2.8-6.5 \mathrm{pmol} / \mathrm{L}$ ), with positive aTPO; patients with subclinical hypothyroid function (TSH: $4.5-10 \mu \mathrm{IU} / \mathrm{mL}$, normal or low values for $\mathrm{FT}_{4}$ and $\mathrm{FT}_{3}$ ) with positive aTPO; patients with hypothyroid function ( $\mathrm{TSH}>10 \mu \mathrm{IU} / \mathrm{mL}$, low values for $\mathrm{FT}_{4}$ and $\mathrm{FT}_{3}$ ) with positive aTPO.

The exclusion criteria were: patients with hyperthyroid function and positive aTPO; patients treated with drugs that interfere with thyroid function and pregnancy in the last 12 months before enrolment.

\section{Se treatment}

All patients were treated with increasing Se therapy, according to the levels of elevation of aTPO: 1) Patients with titer of aTPO $>1,000 \mathrm{IU} / \mathrm{mL}$ were treated with three tablets/day $(150$ $\mu \mathrm{g} \mathrm{Se})$; 2) Patients with titer of aTPO between 500 and 1,000 $\mathrm{IU} / \mathrm{mL}$ were treated with two tablets/day $(100 \mu \mathrm{g} \mathrm{Se}) ; 3) \mathrm{Pa}-$ tients with titer aTPO between 50 and $500 \mathrm{IU} / \mathrm{mL}$ were treated with one tablet/day $(50 \mu \mathrm{g} \mathrm{Se})$.

Patients who showed normal values of the TSH ( $\mathrm{n}=181$, $36 \%$ ) (euthyroid form of HT) as well as those that presented as subclinical form of hypothyreosis were treated with Se only, while patients with TSH $>10(\mathrm{n}=319,64 \%)$ were treated with both substitutional therapy of levothyroxine $\left(\mathrm{LT}_{4}\right)$ plus Se therapy. We evaluated the changes in the level of aTPO and also the volume and changes in the ultrasonographic features in a 1-year period duration of treatment.

\section{Results}

Regarding the thyroid status of the patients, out of 500 patients, $178(36 \%)$ presented with aTPO $>1,000 \mathrm{IU} / \mathrm{mL}, 150$ (30\%) had aTPO between 500 and $1,000 \mathrm{IU} / \mathrm{mL}$ and 172 $(34 \%)$ had aTPO $<500 \mathrm{IU} / \mathrm{mL}$. Around $37 \%$ of patients with initial value of aTPO $>1,000 \mathrm{IU} / \mathrm{mL}$, treated with $\mathrm{Se} 3 \times 50$ $\mu \mathrm{g} /$ day, showed treatment effect after the first 3 months of the treatment: 10/178 (5.62\%) lowered the titer of aTPO below $500 \mathrm{IU} / \mathrm{mL}$, and 56/178 (31.46\%) had aTPO between 500 and $1,000 \mathrm{IU} / \mathrm{mL}$. But at the end of the treatment (after 12 months) in only $67 / 178(37.64 \%)$ aTPO remained unchanged, while $43 / 178(24.16 \%)$ had aTPO $<500 \mathrm{IU} / \mathrm{mL}$ and $68 / 178(38.20 \%)$ had aTPO between 500 and 1,000 IU/mL $(\mathrm{P}<0.04)$ (Fig. 1).

From 150 patients with the initial value of aTPO between 500 and $1,000 \mathrm{IU} / \mathrm{mL}$, treated with Se $2 \times 50 \mu \mathrm{g} /$ day, treatment effect with aTPO $<500 \mathrm{IU} / \mathrm{mL}$ was registered in $39(26 \%)$ patients in the first 3 months of treatment, $48(32 \%)$ in the period of 3 - 6 months after treatment, 64 (42.67\%) 6 - 9 months after treatment and $83(55.33 \%) 1$ year after treatment (Fig. $2)$. More than half of the patients $(91 / 172,52.90 \%)$ who had aTPO $<500 \mathrm{IU} / \mathrm{mL}$ and were treated with Se dose of $50 \mu \mathrm{g} /$ day normalized in a period of 1 year $(\mathrm{P}<0.02)$ (Fig. 3$)$.

Mainly patients that had high titer of aTPO $>1,000 \mathrm{IU} / \mathrm{mL}$ $(\mathrm{n}=142,44.50 \%)$, or aTPO in the range of $500-1,000 \mathrm{IU} / \mathrm{mL}$ $(\mathrm{n}=101,31.66 \%)$ suffered also from hypothyroidism, while the highest percent of the euthyroid patients $(\mathrm{n}=96,53.03 \%)$ had lower titer of aTPO $<500 \mathrm{IU} / \mathrm{mL}(\mathrm{P}<0.03)$ (Fig. 4),

In the hypothyroid group of patients treated with both levothyroxine and Se, we evaluated the response of this combination of therapy in a period from 3 months interval up to 12 months interval after treatment. We demonstrated significantly lower titer of aTPO in the group of patients with the initial level of aTPO $>1,000 \mathrm{IU} / \mathrm{mL}(\mathrm{n}=142$ at initial phase, $\mathrm{n}=67$ after 12 months, $47.18 \%$ responded), as well as in the group 


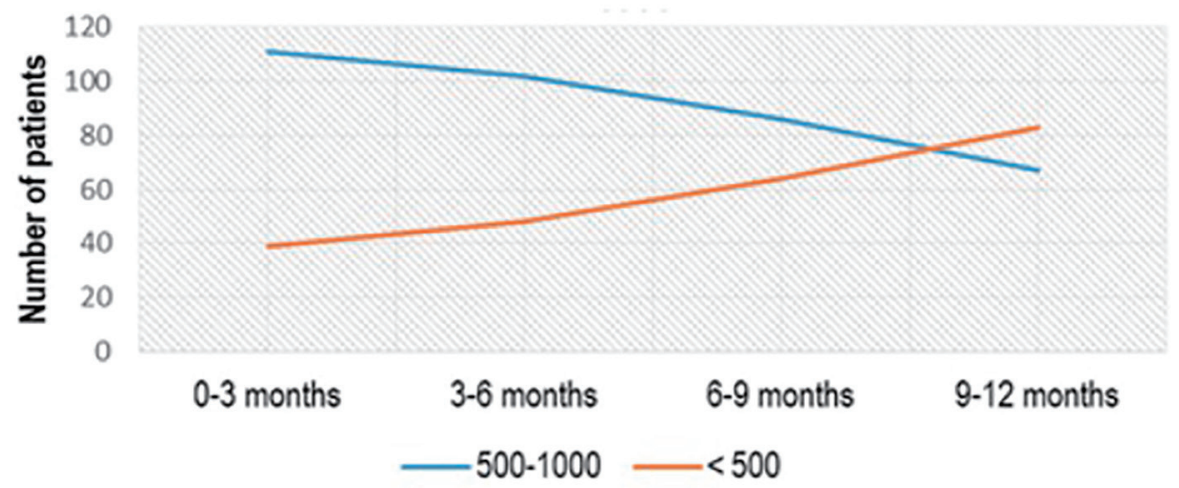

Figure 2. aTPO level after Se $(2 \times 50 \mu \mathrm{g})$ administration in the subgroup with initial aTPO between 500 and 1,000 IU/mL. aTPO: anti-thyroid peroxidase; Se: selenium.

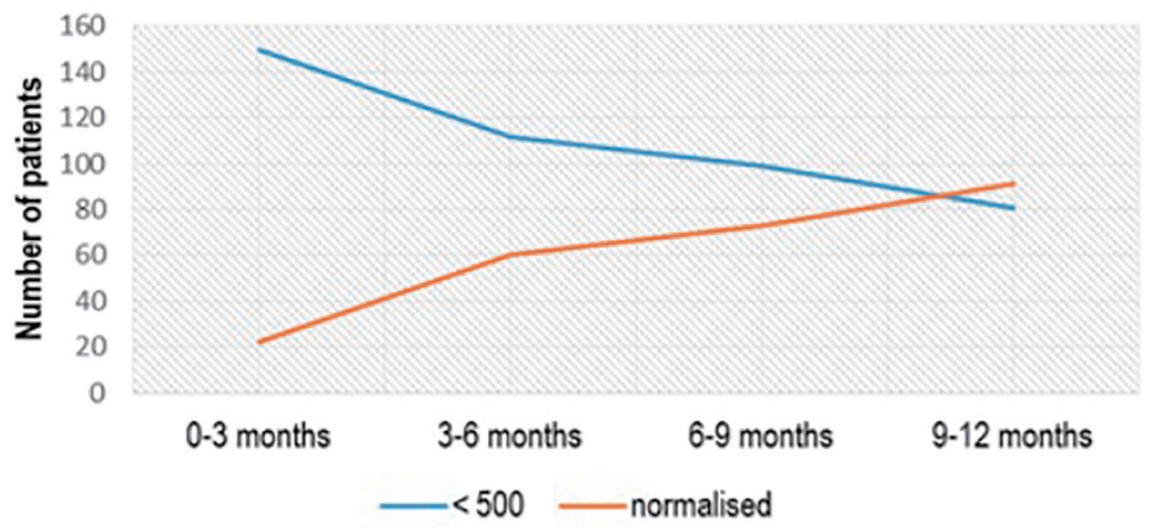

Figure 3. aTPO level after Se $(1 \times 50 \mu \mathrm{g})$ administration in the subgroup with initial aTPO < $500 \mathrm{IU} / \mathrm{mL}$. aTPO: anti-thyroid peroxidase; Se: selenium.

with the initial level of aTPO between 500 and $1,000 \mathrm{IU} / \mathrm{mL}$ $(\mathrm{n}=101$ at initial phase, $\mathrm{n}=80$ after 12 months, $79.20 \%$ re- sponded) (Fig. 5).

In the euthyroid group of patients $(\mathrm{n}=181,36.2 \%)$ treated

\section{Qhypothyroidism seuthyroid}

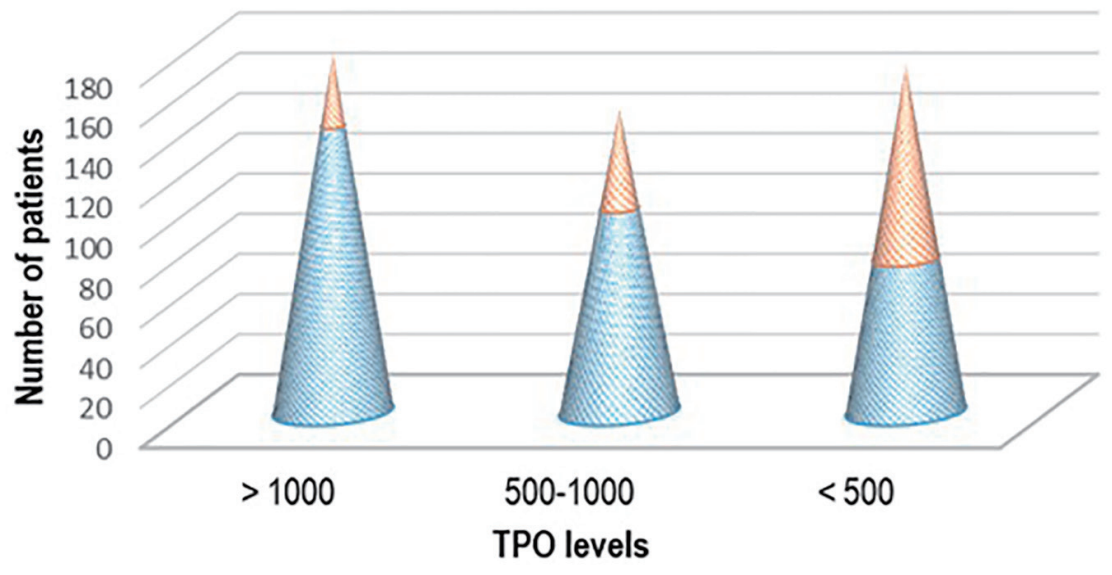

Figure 4. Thyroid status regarding the titer of aTPO. aTPO: anti-thyroid peroxidase. 


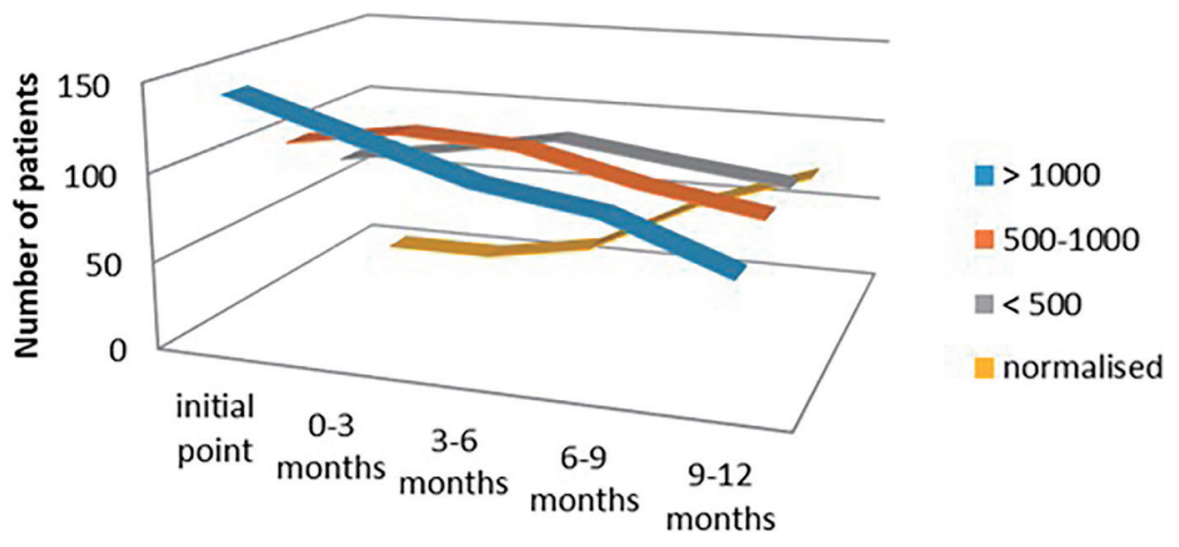

Figure 5. aTPO level after selenium + levothyroxine administration in the hypothyroid group. aTPO: anti-thyroid peroxidase.

with Se therapy only, we also found significant lowering of the titer of aTPO. In the subgroup with aTPO $>1,000 \mathrm{IU} / \mathrm{mL}$, $25 / 36(69.44 \%)$ remained with high aTPO $>1,000 \mathrm{IU} / \mathrm{mL}$, while $30.56 \%$ responded after 1 year of Se treatment. Despite this, very small percent of response was noticed in the other two subgroups: only $4.05 \%$ responded with aTPO between 500 and $1,000 \mathrm{IU} / \mathrm{mL}$, the same as at the initial phase, and $7.29 \%$ responders were seen with initial titer of aTPO $<500$
IU/mL $(\mathrm{P}<0.03)$ (Fig. 6).

In the age group above 50 years, when the initial titer of aTPO was above $1,000 \mathrm{IU} / \mathrm{mL}(\mathrm{n}=108,21.6 \%)$ or between 500 and $1000 \mathrm{IU} / \mathrm{mL}(\mathrm{n}=65,13 \%)$, we found significantly lower titer of aTPO, in the follow-up period of 12 months, $41.67 \%$ and $46.15 \%$ responded, respectively. Very good response of lowering the titer of aTPO was seen in the age group of 30 - 50 years. In this group, $16 / 30(53.33 \%)$ remained with

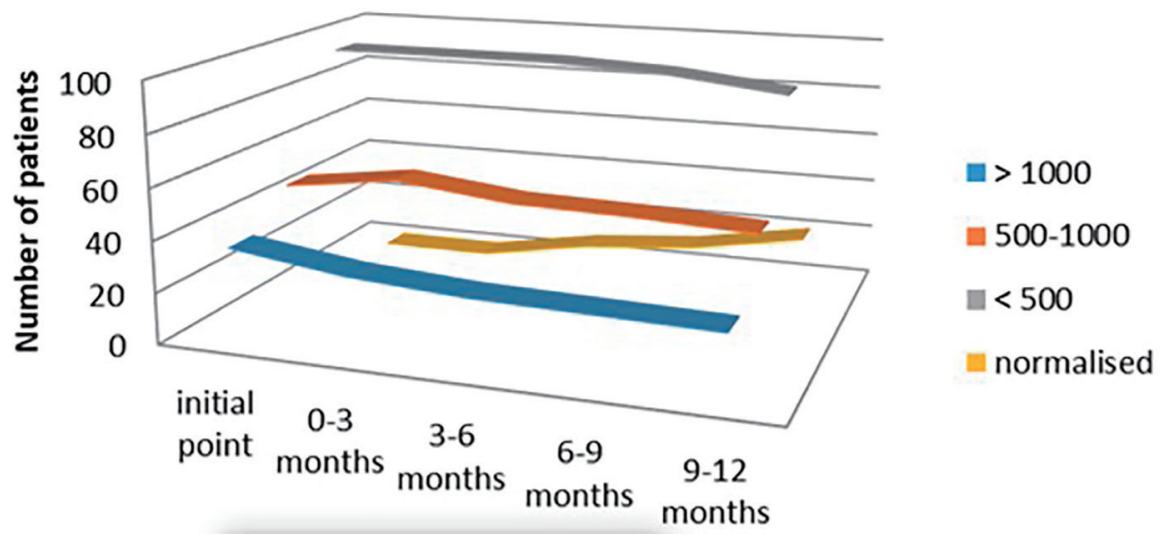

Figure 6. aTPO level after selenium administration in the euthyroid group. aTPO: anti-thyroid peroxidase.

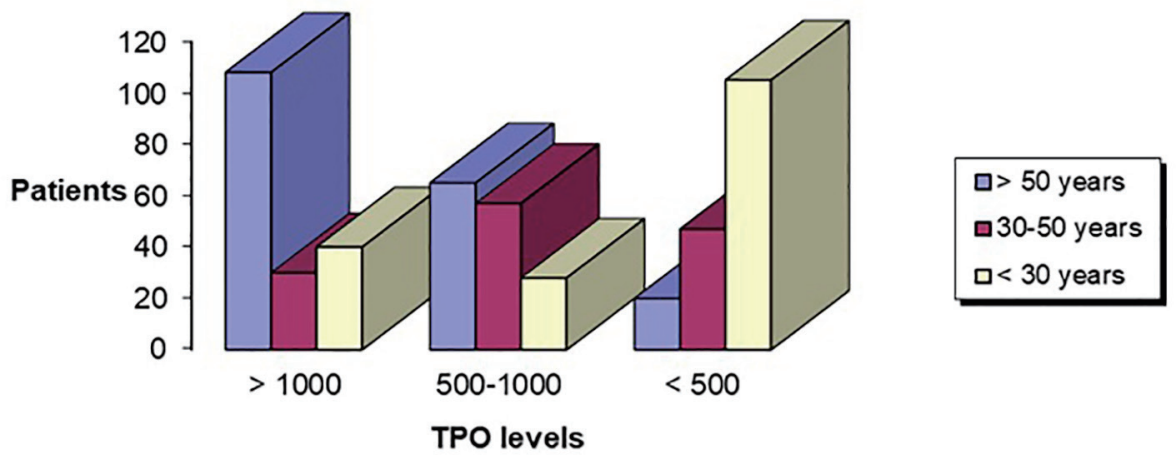

Figure 7. Age in correlation with aTPO level. aTPO: anti-thyroid peroxidase. 
the initial value of aTPO $>1,000 \mathrm{IU} / \mathrm{mL}$, while $46.67 \%$ responded. Patients who had initial value of aTPO between 500 and $1,000 \mathrm{IU} / \mathrm{mL}, 66.67 \%$ remained the same, while $33.33 \%$ responded (after 1 year had lower levels of aTPO). Very low percentage of response $(17.02 \%)$ was seen in this age group with aTPO $<500 \mathrm{IU} / \mathrm{mL}$, while $39 / 47(82.98 \%)$ were nonresponders (Fig. 7).

All patients had thyroid ultrasound imaging suggestive of chronic thyroiditis with typical hypoechogenicity. Taking into account the thyroid volume, we found that atrophy of the thyroid was more associated in the group with the lowest titer of aTPO $<500 \mathrm{IU} / \mathrm{mL}$, while those with highest titer of aTPO $>$ $1,000 \mathrm{IU} / \mathrm{mL}$ had enlarged thyroid volume.

\section{Discussion}

In view of the pivotal role of Se in thyroid physiology, it is conceivable that Se supplementation may be of benefit to patients with HT, particularly in clinical situations of Se deficiency [5]. Several studies have suggested that Se treatment reduces antibodies levels, allows lower dosage of $\mathrm{LT}_{4}$ supplementation and may provide other beneficial effects in patients with HT.

Interest in interactions between Se and iodine deficiency first arose in 1980s from the discovery that Se is essential for normal thyroid hormone metabolism. It was first recognized as an elevated plasma thyroxine $\left(\mathrm{T}_{4}\right)$ concentration and a decreased plasma $3,3^{\prime}, 5$ triiodothyronine $\left(\mathrm{T}_{3}\right)$ concentration in Se-deficient animals $[6,7]$. Few years later, when children in Central Africa with iodine and Se deficiencies were supplemented with Se alone, it was discovered that thyroid destruction and myxedematous cretinism was developed, suggesting that Se should not be supplemented prior to correction of the iodine deficit [8].

Se plays a key role in the thyroid cell physiology, incorporated in the molecular structure of several enzymes like glutathione peroxidase, critically involved in protecting the gland against oxidative damage, as well as degradation of $\mathrm{H}_{2} \mathrm{O}_{2}$ to water and the other important enzyme is iodothyronine deiodinases involved in producing active form of thyroid hormones.

TPO catalyzes the biosynthesis of thyroid hormones and is a major auto-antigen in Hashimoto's disease. Hydrogen peroxide $\left(\mathrm{H}_{2} \mathrm{O}_{2}\right)$ is a substrate in catalyzing the iodination and coupling of tyrosyl residues in thyroglobulin to produce thyroid hormone. Furthermore, as a free radical, it is capable of inflicting oxidative damage. Se deficiency contributes to improper function of these two enzymes, thus resulting in ineffective production of $T_{3}$, inefficient protection against free radicals, and further on facilitating cell damage and auto-immune gland destruction [4].

We performed a prospective, randomized, longitudinal, interventional study to assess the effects of Se supplementation for HT. We have similar number of the patients in the three groups of aTPO: $36 \%$ had aTPO > 1,000 IU $/ \mathrm{mL}, 34 \%$ had aTPO $<500 \mathrm{IU} / \mathrm{mL}$, while around $30 \%$ had titer in between 500 and $1,000 \mathrm{IU} / \mathrm{mL}$. We detected nearly $50 \%$ or more response in each of the three groups treated with Se: $63 \%$ lowering the titer of aTPO $<500 \mathrm{IU} / \mathrm{mL}$ if treated with Se $3 \times 50$ $\mu \mathrm{g} /$ day, $55.33 \%$ lowering of aTPO if treated with Se $2 \times 50$ $\mu \mathrm{g} /$ day and lowering or normalizing the aTPO levels in nearly $53 \%$ if treated with Se $50 \mu \mathrm{g} /$ day. Consecutive lowering of the aTPO level was noticed in every following 3 months up to 12 months, thus increasing the number of patients with titer below $500 \mathrm{IU} / \mathrm{mL}$. This indicated that at least nearly 1 year is needed for and in-depth assessment of Se treatment in HT.

Observational period of 1 year was used by Mazokopakis et al who prospectively studied 80 women with HT orally treated with $200 \mu \mathrm{g}$ Se (40 treated during a 6-month period and 40 patients treated for 1 year). They showed significant reduction of serum aTPO levels during the first 6 months (by 5.6\% and $9.9 \%$ at 3 and 6 months, respectively). The continuation of Se supplementation up to 1 year resulted in an additional $8 \%$ decrease of aTPO compared with the basal values, while the cessation caused a $4.8 \%$ increase in the aTPO concentrations [9].

Some studies evaluated Se effect only in 3-month or 6-month periods. In the study of Toulis et al significantly lower aTPO titers were demonstrated after only 3 months Se supplementation (four studies, random effects weighted mean difference: $-271.09,95 \%$ confidence interval: -421.98 to -120.19 , $\mathrm{P}<0.0001$ ), and improvement in mood and/or general wellbeing was noted (three studies, random effects risk ratio: 2.79, 95\% confidence interval: $1.21-6.47, \mathrm{P}=0.016$ ) when compared with controls. They have concluded that different pattern of response to Se supplementation was associated with the baseline aTPO titers in HT that can be used to identify which patients would benefit most from treatment [5].

Positive effect of Se therapy was described in the study of Turker et al. Oral administration of $200 \mu \mathrm{g} \mathrm{Se} /$ day for 3 months effectively decreased serum aTPO titers (from 803.9 \pm 83.8 to $572.3 \pm 17.3 \mathrm{IU} / \mathrm{mL}, 26.2 \%$ decrement, $\mathrm{P}<0.001$ ), while in the placebo group, there was insignificant change (from $770.3 \pm 06.2$ to $773.4 \pm 72.9 \mathrm{IU} / \mathrm{mL}, \mathrm{P}>0.05$ ). These authors found out that lower supplementation dose of Se (100 $\mu \mathrm{g} /$ day) showed increase in aTPO for $38.1 \%$, while supplementation of $200 \mu \mathrm{g} /$ day showed decrease of aTPO for $26.2 \%$ in the first 6 months [10].

In a blinded, placebo-controlled trial, Gartner et al observed that in the group of HT females receiving $200 \mu \mathrm{g}$ ( 2.53 $\mu \mathrm{mol})$ sodium selenite per day, orally for 3 months, the mean aTPO concentration decreased significantly $(63.6 \%$ vs. $88 \%$ in the placebo group) [11].

Similarly, a study conducted by Zhu et al in 2012 on autoimmune thyroiditis patients with different thyroid functional status revealed that Se supplementation with $200 \mu \mathrm{g}$ for 6 months resulted in the reduction of aTPO concentration $(12.6 \%$ in subclinical and $20.4 \%$ in the overt form of the disease) [12].

In 2003, Duntas et al performed a randomized, placebocontrolled prospective study to investigate the effects of Se treatment on 65 patients with auto-immune thyroiditis. They divided the patients in two groups, group I $(\mathrm{n}=34)$ was treated with Se $200 \mu \mathrm{g}$, plus $\mathrm{LT}_{4}$, whereas group II $(\mathrm{n}=31)$ received $\mathrm{LT}_{4}$ plus placebo over a period of 6 months. No significant difference was noted between groups, although there was a decrease of $46 \%$ at 3 months and $55.5 \%$ at 6 months in group I vs. $21 \%$ and $27 \%$ respectively in group 2 [13].

In our study, we also evaluated the link between the age 
and the titer of aTPO. The highest titer of aTPO was associated with younger patients, while older patients had lowest titer $($ aTPO $<500 \mathrm{IU} / \mathrm{mL})$. No relationship was found between the age and the response rate to the treatment in the study of Turker. Thus, treatment should be started at an early age to save more thyrocytes, otherwise, it may be ineffective in atrophic phase of the pathology. They have also noted sharp decrease in serum aTPO levels at the beginning of Se treatment, in patients with relatively high serum titers [10].

TPO is a poorly glycosylated intracellular microsomal antigen, membrane-bound enzyme, responsible for iodine $\left(\mathrm{I}_{2}\right)$ oxidation and iodination of tyrosyl residues of the Tg molecule [14]. Polyclonal antibodies from healthy individuals and patients are directed against the epitopes. Destruction of the thyrocytes $>90 \%$ leads to hypothyroidism and thus higher levels of antibodies against Tg and TPO promote progression to hypothyroidism [15].

Regarding the patient status, more significant lowering of the aTPO titer from the initial point was found in the hypothyroid group of patients vs. euthyroid. The effect of Se is already evaluated in several studies, although in a smaller group of patients.

So far in the literature we have not found an article that divided the patients in groups regarding the titer of aTPO and in that way ordinate the dose of Se. Usually total Se dose per day ranged from 150 to $200 \mu \mathrm{g}$. We have used lower dose of Se where aTPO was lower, while as it increased we increased the therapeutic dose of Se, with starting point of $50 \mu \mathrm{g}$ up to $150 \mu \mathrm{g}$. Lower doses of Se was used in a prospective study by Nacamulli et al. They revealed reduced echogenicity of the thyroid and lower levels of aTPO and aTg, using supplementation with physiological doses of Se $(80 \mu \mathrm{g} /$ day of sodium selenite) for 12 months, without significantly affecting the concentration of $\mathrm{TSH}$ or $\mathrm{T}_{4}$ [16].

Moreover, the pharmacokinetics of selenomethionine were studied in 10 patients and eight volunteers at baseline and 2, 4, 6 and $24 \mathrm{~h}$ after oral administration of a $200 \mu \mathrm{g}$ tablet of selenomethionine. Finally, Se levels were measured at the end of the study in some patients of both groups and their results were correlated with thyroid hormone levels [15].

According to the Polish research, the average content of Se in serum of patients with Hashimoto disease $(63.03 \pm 17.31$ $\mu \mathrm{g} / \mathrm{L})$ was significantly lower $(\mathrm{P}<0.0007)$ in comparison with the control group $(75.16 \pm 19.92 \mu \mathrm{g} / \mathrm{L})$ [17]. Similarly, Erdal et al revealed lower levels of Se in serum of patients with HT $(67.7 \pm 10.4 \mathrm{mg} / \mathrm{L})$ as compared to the control group $(83.7 \pm$ $17.3 \mathrm{mg} / \mathrm{L})$ [18].

The role of Se supplementation to restore euthyroidism in at least one-third of subclinical hypothyroid patients with autoimmune thyroiditis was observed by Pirola in 2016. From 192 patients, one group received $83 \mu \mathrm{g}$ Se/day orally for 4 months, and the others were controls who did not receive any treatment. At the end of the study, 33/192 (17.2\%) participants restored euthyroidism, that was significantly more frequent among treated patients vs. controls (30/96 (31.3\%) vs. 3/96 $(3.1 \%), \mathrm{P}<0.0001)[19]$.

Unresponsiveness of many HT patients to Se therapy is interesting. The cohort study carried out by Karanikas et al in 2008 demonstrated that Se administration in HT patients did not induce significant immunological changes, in terms of aTPO levels (524 \pm 452 vs. $505 \pm 464 \mathrm{IU} / \mathrm{mL}$; P > 0.05) [20]. Although we can find in the literature some studies that show no improvement in the aTPO level despite Se treatment, still more long-term, randomized controlled, multicenter trials are needed to evaluate the beneficial effects of the Se supplementation in HT patients.

\section{Conclusion}

The results of our study demonstrate, as in the literature findings, that at present, there is a benefit of the use of Se supplementation for the treatment of patients with HT. Furthermore, well-designed randomized placebo-controlled trials on Se treatment in HT are still needed and can be used in future for clinical decision making.

\section{Acknowledgments}

Not applicable.

\section{Financial Disclosure}

We have nothing to declare.

\section{Conflict of Interest}

We have no conflict of interest.

\section{Informed Consent}

All patients had full filed informed consent for entering the study.

\section{Author Contributions}

Nevena Manevska: patient selection and treatment, materials and methods, discussion, results. Sinisa Stojanoski: patient selection and treatment, materials and methods, results and conclusion. Tanja Makazlieva: patient selection and treatment, materials and methods, results.

\section{References}

1. https://ods.od.nih.gov/factsheets/Selenium-Health Professional/\#en3.

2. Terry EN, Diamond AM. Selenium. In: Erdman JW, Macdonald IA, Zeisel SH, eds. Present Knowledge in Nutrition. 10th ed. Washington, DC: Wiley-Blackwell; 2012. p. $568-587$.

3. Drutel A, Archambeaud F, Caron P. Selenium and the 
thyroid gland: more good news for clinicians. Clin Endocrinol (Oxf). 2013;78(2):155-164.

4. Kohrle J, Jakob F, Contempre B, Dumont JE. Selenium, the thyroid, and the endocrine system. Endocr Rev. 2005;26(7):944-984.

5. Toulis KA, Anastasilakis AD, Tzellos TG, Goulis DG, Kouvelas D. Selenium supplementation in the treatment of Hashimoto's thyroiditis: a systematic review and a meta-analysis. Thyroid. 2010;20(10):1163-1173.

6. Arthur JR, Nicol F, Boyne R Allen KGJ, Hayes JD, Beckett GJ. Old and new roles for selenium. In: Trace Substances in Environmental Health. 1987;XXI:487-498.

7. Beckett GJ, Beddows SE, Morrice PC, Nicol F, Arthur JR. Inhibition of hepatic deiodination of thyroxine is caused by selenium deficiency in rats. Biochem J. 1987;248(2):443-447.

8. Contempre B, Dumont JE, Ngo B, Thilly CH, Diplock AT, Vanderpas J. Effect of selenium supplementation in hypothyroid subjects of an iodine and selenium deficient area: the possible danger of indiscriminate supplementation of iodine-deficient subjects with selenium. J Clin Endocrinol Metab. 1991;73(1):213-215.

9. Mazokopakis EE, Papadakis JA, Papadomanolaki MG, Batistakis AG, Giannakopoulos TG, Protopapadakis EE, Ganotakis ES. Effects of 12 months treatment with Lselenomethionine on serum anti-TPO Levels in Patients with Hashimoto's thyroiditis. Thyroid. 2007;17(7):609612 .

10. Turker O, Kumanlioglu K, Karapolat I, Dogan I. Selenium treatment in autoimmune thyroiditis: 9-month followup with variable doses. J Endocrinol. 2006;190(1):151156.

11. Gartner R, Gasnier BC, Dietrich JW, Krebs B, Angstwurm MW. Selenium supplementation in patients with autoimmune thyroiditis decreases thyroid peroxidase antibodies concentrations. J Clin Endocrinol Metab. 2002;87(4):1687-1691.
12. Zhu L, Bai X, Teng WP, Shan ZY, Wang WW, Fan CL, Wang $\mathrm{H}$, et al. [Effects of selenium supplementation on antibodies of autoimmune thyroiditis]. Zhonghua Yi Xue Za Zhi. 2012;92(32):2256-2260.

13. Duntas LH, Mantzou E, Koutras DA. Effects of a six month treatment with selenomethionine in patients with autoimmune thyroiditis. Eur J Endocrinol. 2003;148(4):389393.

14. McLachlan SM, Rapoport B. The molecular biology of thyroid peroxidase: cloning, expression and role as autoantigen in autoimmune thyroid disease. Endocr Rev. 1992;13(2):192-206.

15. Marcocci C, Marino M. Thyroid-directed antibodies. In: Braverman LE, Utiger R, editors, editors. Part II Laboratory Assessment of Thyroid Function. Philadelphia, PA: Lippincott Williams and Wilkins; 2005. p. 360-372.

16. Nacamulli D, Mian C, Petricca D, Lazzarotto F, Barollo S, Pozza D, Masiero S, et al. Influence of physiological dietary selenium supplementation on the natural course of autoimmune thyroiditis. Clin Endocrinol (Oxf). 2010;73(4):535-539.

17. Socha K, Dziemianowicz M, Omeljaniuk W. Nawyki zywieniowe a stezenie selenu w surowicy u pacjentow $\mathrm{z}$ choroba Hashimoto. Probl Hig Epidemiol. 2012;93(4):824-827.

18. Erdal M, Sahin M, Hasimi A, Uckaya G, Kutlu M, Saglam $\mathrm{K}$. Trace element levels in hashimoto thyroiditis patients with subclinical hypothyroidism. Biol Trace Elem Res. 2008;123(1-3):1-7.

19. Pirola I, Gandossi E, Agosti B, Delbarba A, Cappelli C. Selenium supplementation could restore euthyroidism in subclinical hypothyroid patients with autoimmune thyroiditis. Endokrynol Pol. 2016;67(6):567-571.

20. Karanikas G, Schuetz M, Kontur S, Duan H, Kommata S, Schoen R, Antoni A, et al. No immunological benefit of selenium in consecutive patients with autoimmune thyroiditis. Thyroid. 2008;18(1):7-12. 